\title{
The Reliability of Nutrition Fact Labels on Sugar Sweetened Beverages in Suriname
}

\author{
Cheuk-A-Lam Gerani ${ }^{*}$, Stutgard Ricky ${ }^{1}$ \\ ${ }^{1}$ Anton de Kom University of Suriname, Faculty of Engineering, Paramaribo/ Suriname
}

\begin{abstract}
Introduction: Nutrition information on food labels is an important source of information which may influence consumers' purchasing behavior and health. Therefore, it is of eminent importance that manufacturers provide reliable nutrition information on food labels. Unfortunately, food labelling regulations and policy measures for the control on the reliability of nutrition labels are often lacking or underutilized; especially in developing countries such as Suriname.

Objective: The objective of the study was to measure the reliability of the declared sugar content on the nutrition labels of the most consumed sugar-sweetened beverages in Suriname.

Design \& Methods: In accordance with the results of a consumer survey $(\mathrm{N}=155)$, the reliability of the declared sugar content on nutrition labels, of the 6 most consumed sodas and 6 most consumed prepackaged fruit juices, were determined via Brix analyses $(\mathrm{N}=72)$. To determine whether there was a significant difference, the average measured value was compared with the declared sugar content on the nutrition label via a two-sided test $(\alpha=5 \%)$ in SPSS.

Results: When comparing the average measured value with the declared sugar content on the nutrition labels of sodas, we found a significant difference between 4 out of 6 brands (67\%). These brands had significantly lower sugar contents than the nutrition label declared. The average measured value of all the juices under investigation differed from the value indicated on the nutrition label; 4 brands had significantly lower, while 2 brands had significantly higher sugar contents (p $<0.05)$.

Conclusion: An investigation of nutrition labelling on SSBs in Paramaribo, showed that declared sugar contents on nutrition labels may not always be accurate. In this study, the majority of declared sugar values in sodas where luckily lower than the average measured values. However, we must be mindful of chances of instrumentational and observational errors. Nonetheless, 2 fruit juices had significantly higher sugar contents than declared on their nutrition label. This can be harmful for consumers with medical conditions such as diabetes, and may hamper consumers' right to reliable and safe nutrition information. Therefore, it is advisable that manufacturers ensure the declaration of trustworthy nutritional values; especially when it concerns products with high implications for adverse health effects. Hence, a policy plan for the development, control and monitoring of nutrition information in Suriname is of paramount importance.
\end{abstract}

Keywords: Food packaging, nutrition, labelling, sugar-sweetened beverages

\section{Introduction}

Every consumer has the right to know the right composition and ingredients of their food products via information on food labels, and to what extent this information is reliable. Especially when it concerns ingredients such as free sugars which, when consumed regularly, have a harmful impact on our health [1].
Corresponding Author: Cheuk-A-Lam Gerani, Anton de Kom University of Suriname, Faculty of Engineering, Paramaribo, Suriname. Received date: July 08, 2020; Accepted date: August 31, 2020; Published date: September 02, 2020.

DOI: https://doi.org/10.31546/2633-7924.1011 
As the World Health Organization states: "Free sugars contribute to the overall energy density of diets and higher intakes of free sugars provide significant energy without specific nutrients, leading to unhealthy weight gain and increased risk of obesity and various NCDs [10]". Sugarsweetened beverages such as sodas and prepackaged fruit juices usually have high concentrations of free sugars.

Food package labelling represents the identity card of food products and should on the one hand, contain legally required information such as composition and ingredients (allergies) and their relative amounts (i.e. nutrition labelling). While on the other hand, the information on food packaging should be reliable, easy to understand and should prevent consumers from danger in terms of food intoxications. Nutrition labelling for prepacked food became mandatory in Europe since December 2011, when the Regulation (EU) No1169/2011 came into effect. The regulation establishes the conditions for a standardized label writing in form and content, and nutritional declaration. Manufacturers have to declare the energy value of the product as well as 6 nutrients and their amounts (i.e. fat, saturates, carbohydrate, sugars, proteins, salt) expressed per $100 \mathrm{~g}$ or $100 \mathrm{ml}$ of product. Food labelling also informs consumers about the net weight, expiration date, and origin of the product [2-12].

Nutrition labelling can be a guide in protecting and improving consumers' health, and in a wider perspective significantly impact on public health in terms of costs for individuals and medical systems [13-19]. As such, health conscious consumers, and those who are advised to consume healthier diets due to medical conditions, are entitled to receive reliable food packaging information when composing their meal plan. Unfortunately, food labeling rules and regulations are often lacking or adherence to these regulations is not effectively monitored in developing countries. This is also the case in Suriname. Hence, a policy plan for the development, control and monitoring of food packaging information in Suriname is of paramount importance. In addition, it offers Surinamese Agro-processors the opportunity to compete on the international market based on qualitative food labeling. As such, the objective of this study was to measure whether the declared sugar content on sugar-sweetened beverages in Suriname, corresponded with the average measured value of the products.

\section{Materials and Methods Consumer survey}

As there was no previous data on the consumption behavior of citizens in Paramaribo, with specific regards to their frequency and type of SSB consumption, an exploratory study on these matters was started. The survey took place in the capital of Suriname, Paramaribo, and included participants in the age range of 16 to $64(\mathrm{~N}=155)$. Within the capital city, Paramaribo is divided into 12 main resorts. Depending on the number of citizens in each resort, we calculated the minimum number of respondents required to increase the validity of the study. Afterwards, we randomly selected the required number of participants in each resort based on their willingness to participate voluntarily. At first, participants were orally and in writing introduced to the objective, stakeholders and the confidentiality of the study. Afterwards respondents were interviewed on their sociodemographic factors, knowledge about nutrition labels, and their consumption behavior of SSBs.

\section{Sugar content analyses via Brix measurement}

Based on the results of the consumer survey, the most reported sugar-sweetened beverage groups (i.e. sodas and prepackaged fruit juices) were investigated. In each product group, 6 different brands ( 3 per product brand) were analyzed. Thus, we analyzed 6 soda brands and 6 fruit juice brands. Of each brand, we collected 3 random independent samples, which resulted in a total of 18 sodas and 18 fruit juices. As such, there was a total of 36 SSBs under investigation. Each sample was tested twice $(\mathrm{N}=72)$, after which we reported the average value of 6 measurements per brand. The product packaging and nutrient information were recorded to obtain the sugar content $(\mathrm{g} / 100 \mathrm{ml})$. The average measured value was then compared with the literature value and the sugar content mentioned on the nutrition fact label. Brix measurement (or Brix scale) is a well-known application in the food and beverage industry used to measure sugar content in substances such as soft drinks and fruit juices. The sugar content in soft drinks and juices were measured by the use of a digital refractometer and determined in gr / $100 \mathrm{gr}$ or ${ }^{\circ}$ Brix. The Brix value is a measure of the amount of dissolved sugars in an aqueous liquid and indicates how much mass percentage of the liquid consists of sugars. First, the refractometer was warmed-up for 30 minutes and the prism was prerinsed 3 times by placing a drop of distilled water on it each time. Afterwards, the refractometer was adjusted to the cross. Next, the prism was rinsed with the sample to be investigated. At last, a drop of the sample was placed on the dry prism of the refractometer making it possible to read its sugar content. The reported sugar content was the average value of 2 measurements [20-23]. 


\section{Statistical analyses}

The data was analyzed in IBM SPSS Statistics 20. For consumer perceptions and measurements of SSB frequency consumption, descriptive statistics and the Chi-square test with a significance level of $\alpha=5 \%$, were used. The differences between the average measured value and the declared nutrition label value is determined by the two-sided test at a significance level of $\alpha=5 \%$.

\section{Results}

\section{Consumer survey - SSB frequency consumption}

From the consumer survey we concluded that the most consumed SSBs in Suriname were: Fernandes soft drinks, Coca-Cola, Fanta, Elmer, Coropina and More Juice. Fernandes soft drinks $(53.5 \%)$ and Coca-Cola $(25.8 \%)$ were the most consumed carbonated beverages in Paramaribo. The most consumed prepackaged fruit juice brands were: More Juice (21.3\%), Elmer Juice (20.6\%) and Coropina (16.1\%). Out of the 155 respondents, $13.5 \%$ indicated to consume soft drinks and / or fruit juices maximum once per week, $14.2 \%$ did this a maximum of 2 times per week, $31.6 \%$ between 2 - 4 times per week and the largest group (40\%) indicated to consume sugarcontaining drinks more than 4 times per week.

\section{Product analyses}

Table 1: Comparison of measured sugar content vs. nutrition label value of soda brands in Suriname

\begin{tabular}{|l|l|l|l|l|}
\hline Brands & $\begin{array}{l}\text { Average } \\
\text { measured } \\
\text { value } \pm \text { S.E } \\
(\mathbf{g} / 100 \mathrm{ml})\end{array}$ & $\begin{array}{l}\text { Nutrition } \\
\text { fact label } \\
(\mathbf{g} / \mathbf{1 0 0 m l})\end{array}$ & $\begin{array}{l}\text { Mean } \\
\text { difference } \\
(\mathbf{g} / \mathbf{1 0 0 m l})\end{array}$ & $\begin{array}{l}\text { Sig. (2- } \\
\text { tailed) }\end{array}$ \\
\hline Fanta Zero (N=6) & $0.09 \pm 0.01$ & 0.7 & -0.62 & 0.000 \\
\hline Cola Light (N=6) & $0.05 \pm 0.03$ & 0 & +0.05 & 0.203 \\
\hline Cola Zero (N=6) & $0.03 \pm 0.02$ & 0 & +0.63 & 0.175 \\
\hline Cola Regular (N=6) & $9.22 \pm 0.07$ & 11.0 & -1.78 & 0.000 \\
\hline $\begin{array}{l}\text { Fernandes red } \\
(\mathrm{N}=6)\end{array}$ & $11.57 \pm 0.16$ & 13.0 & -1.40 & 0.000 \\
\hline $\begin{array}{l}\text { Fernandes green } \\
(\mathrm{N}=6)\end{array}$ & $13.62 \pm 0.05$ & 14.0 & -0.38 & 0.001 \\
\hline
\end{tabular}

In table 1, we see that the sigma value of Fanta Zero, CocaCola Regular, Fernandes green and Fernandes red does not statistically match the average measured value ( $\mathrm{p}<0.05)$, from which it follows that the information on the nutrition label of these SSBs does not correspond with the average measured sugar value. As such, the sugar content of both Fanta Zero, Coca-Cola Regular, Fernandes green and Fernandes red turned out to be significantly lower than the value indicated on the nutrition label. On the contrary, the information on the nutrition label of Coca-Cola Light and Zero did correspond to the average measured value $(p>0.05)$.
Table 2: Comparison of measured sugar content vs. nutrition fact label value of fruit juice brands in Suriname

\begin{tabular}{|l|l|l|l|l|}
\hline Brands & $\begin{array}{l}\text { Average } \\
\text { measured } \\
\text { value } \pm \text { S.E } \\
(\mathbf{g} / \mathbf{1 0 0 m})\end{array}$ & $\begin{array}{l}\text { Nutrition } \\
\text { fact label } \\
\mathbf{( g / 1 0 0 m l})\end{array}$ & $\begin{array}{l}\text { Mean } \\
\text { differenc } \\
\mathbf{e} \\
(\mathbf{g} / \mathbf{1 0 0 m})\end{array}$ & $\begin{array}{l}\text { Sig. (2- } \\
\text { tailed) }\end{array}$ \\
\hline $\begin{array}{l}\text { Elmer Juice } \\
(\mathrm{N}=6)\end{array}$ & $13.08 \pm 0.03$ & 14 & -0.91 & 0.000 \\
\hline $\begin{array}{l}\text { More Juice } \\
\text { (N=6) }\end{array}$ & $11.85 \pm 0.10$ & 13 & -1.15 & 0.000 \\
\hline $\begin{array}{l}\text { Coropina } \\
\text { (N=6) }\end{array}$ & $12.78 \pm 0.07$ & 18 & -5.22 & 0.000 \\
\hline $\begin{array}{l}\text { Jumbo Light } \\
\text { (N=6) }\end{array}$ & $5.12 \pm 0.07$ & 6 & -0.88 & 0.000 \\
\hline $\begin{array}{l}\text { Del Prado Light } \\
\text { (N=6) }\end{array}$ & $4.42 \pm 0.05$ & 4 & +0.42 & 0.000 \\
\hline $\begin{array}{l}\text { Hardthof Light } \\
\text { (N=6) }\end{array}$ & $5.25 \pm 0.08$ & 5 & +0.25 & 0.02 \\
\hline
\end{tabular}

Regardless of the brand and the test value (= nutrition fact label value per brand), the sigma 2-tailed value for each brand was less than alpha $(p<0.05)$. From this we can conclude that the average measured value of all the juice samples examined differed from the value indicated on the nutrition label.

\section{Discussion and Conclusion \\ Nutrition label versus average measured values Sodas}

From table-1, we can conclude that there was a significant difference between the average measured values and the nutrition label information between 4 out of 6 soft drink brands (67\%) under investigation (p $<0.05)$. The sugar content of both Fanta Zero, Fernandes red, Fernandes green and Coca-Cola Regular turned out to be significantly lower than the value indicated on the nutrition label. It is noteworthy that Coca-Cola Light and Zero indicate the sugar content on their nutrition label information as zero because, according to the rounding rules, it is allowed to express the sugar content as zero if a food contains less than 0.5 grams of sugar per $100 \mathrm{ml}$.

As long as a producer does not have extreme lower values stated on his label than actually present in the food, the situation is not alarming or unsafe for consumers' consumption. Nevertheless, it is advisable to state the nutritional value declaration as concretely and precisely as possible.

\section{Fruit juices}

From table-2, we can conclude that the average measured sugar contents of Elmer, More, Coropina and Jumbo Light were lower than the nutritional declaration. 
However, the average measured sugar levels of the 2 Light juices examined were significantly higher than the nutrition label information. The 2 Light juices in question, Del Prado Light and Hardthof Light, may meet the conditions for juices with a "Light claim" according to the Codex Alimentarius guidelines, but the detailed nutritional labelling leaves room for improvement. This can be harmful for consumers with medical conditions such as diabetes, and may hamper consumers' right to reliable and safe nutrition information. Therefore, it is advisable that manufacturers ensure the declaration of trustworthy nutritional values; especially when it concerns products with high implications for adverse health effects.

\section{Conflict of interest}

The authors declare that there are no conflicts of interest.

\section{References}

1. Agarwal S, Hordvik S, Morar S. Nutritional claims for functional foods and supplements. Toxicology. 2006;221:44-49.

2. Ashurst P Ashurst. Chemistry and Technology of Soft Drinks and Fruit Juices. $3{ }^{\text {rd }}$ Ed. Wiley Blackwell.2016.

3. Codex Alimentarius. Codex general guidelines on claims, 1979.

4. Codex Alimentarius. Guidelines for use of Nutrition and Health Claims, 1997. Revised in 2004.

5. Codex Alimentarius. Guidelines on Nutrition Labeling, 1985.

6. Godman H. (Harvard University). FDA's proposed changes to the Nutrition Facts label are good, but could be better - Harvard Health Blog, 2014.

7. http://www.health.harvard.edu/blog/fdas-proposedchanges-nutrition-facts-label-good-better-201407167270

8. Grit C, Smale E. Voedings- en gezondheidsclaims. Sdu uitgevers bv, Den Haag. 2010.

9. Guthrie JF, Morton JF. Food sources of added sweeteners in the diets of Americans. J Am Diet Assoc. 2000;100:4351.

10. Ilaslan K, Ismail HB, Ali T. Rapid analysis of glucose, fructose and sucrose contents of commercial soft drinks usingRaman spectroscopy. Food Control. 2015;48:56-61.

11. Joint WHO/FAO Expert Consultation on Diet, Nutrition and the Prevention of Chronic Diseases (2003). Diet, Nutrition and the Prevention of Chronic Diseases. Geneva, Switzerland. WHO technical report series 916.

12. Joint WHO/FAO. Food Standards Programme \& Codex Alimentarius Commission. Codex Alimentarius. Food labeling complete texts. $4^{\text {th }}$ ed; 2005 .
13. Kasapila W, Shaarani Md. A survey of nutrition labeling on packaged foodstuffs sold in Malawi: Manufacturer practices and legislative issues. Food Control. 2003;30:433-438.

14. Kozup JC, Creyer EH, Burton S. Making healthful food choices: The influence of health claims and nutrition information on consumers' evaluations of packaged food products and restaurant menu items. J Mark. 2003;67:19-34.

15. Lalor F, Kennedy J, Flynn M, Wall P. A study of nutrition and health claims: A snapshot of what's on the Irish market. Public Health Nutr. 2010;13:704-711.

16. Murphy SP, Johnson RK. The scientific basis of recent US guidance on sugars intake. Am J Clin Nutr. 2003;78:827S-833S.

17. Patel A, Smith C, Knowles T, Lin Y. Nutrition and health claims: An enforcement perspective. Trends Food Sci Technol. 2012;28:15-22.

18. Sigman-Grant M. Morita J. Defining and interpreting intakes of sugars. Am J Clin Nutr. 2003;78:815S-826S.

19. Surinaams Standaarden Bureau. SSB 003: 2013 'Algemene vereisten voor het etiketteren van voorverpakte goederen. $1^{\text {st }}$ ed. 2013.

20. Tarabella A, Burchi B. The role of nutrition and health claims in consumers' perception. Creating educational paths to resolve information asymmetries caused by promotion and marketing activities regarding foodstuffs. Procedia - Social and Behavioral Sciences. 2012;46:2173-2177.

21. U.S Food \& Drug Administration.

22. U.S Government Printing Office, Electronic Code of Federal Regulations on Nutrition Food Labelling,

23. Viola GC, Bianchi F, Croce E, Ceretti E. Are Food Labels Effective as a Means of Health Prevention? J Public Health Res. 2016 Dec 9; 5(3): 768. 